\title{
TEM Microstructure Examination of Weld HAZ in Microalloyed Steels
}

\author{
K. Poorhaydari-A, B.M. Patchett and D.G. Ivey
}

Department of Chemical and Materials Engineering, University of Alberta, Edmonton, Alberta, Canada, T6G 2G6

The weld thermal cycle results in significant changes in microstructure, and consequently, mechanical properties of the weld heat-affected zone (HAZ) in steels [1]. To have better control of the properties of HAZ, in particular toughness, an understanding of these changes is required. It is, therefore, of particular interest to examine different sub-regions of the HAZ and compare them with the base metal in terms of microstructure and precipitate characteristics [2]. In this study, microscopical techniques, primarily TEM, were used for characterization of a Grade 100 microalloyed steel. Carbon extraction replicas were used for precipitate characterization in terms of type, chemistry and size distribution. Focused ion beam (FIB) techniques were employed to make site-specific thin foil samples to determine phase structure and precipitation location.

Grade 100 steels contain $<0.10 \mathrm{wt} \% \mathrm{C}$ and approximately a total of $0.2 \mathrm{wt} \% \mathrm{Ti}, \mathrm{Nb}$, and $\mathrm{V}$ as primary microalloying elements. The designation 100 refers to the specified minimum yield strength in 'ksi', 700 MPa. HAZ structures were produced by autogenous welding of the plate (i.e., no filler metal) with heat inputs ranging from 0.5 to $2.5 \mathrm{~kJ} / \mathrm{mm}$ in $0.5 \mathrm{~kJ} / \mathrm{mm}$ steps. Transverse and longitudinal sections were taken. Fig. 1 shows the macrostructure of the weld HAZ with a heat input of $0.5 \mathrm{~kJ} / \mathrm{mm}$ obtained from a transverse section. The main regions of the HAZ are visible in the image, namely the coarse-grained (CG), fine-grained (FG) and intercritical (IC) zones. Also shown are the locations for site-specific FIB samples. One such sample from the base metal (BM) is shown in Fig. 2; the acicular nature of the ferrite is apparent.

HAZ microstructure is dependent on the heat input as well as the distance from the fusion line (the boundary between the weld metal (WM) and the HAZ). The CGHAZ microstructure varies with heat input from ferritic $(2.5 \mathrm{~kJ} / \mathrm{mm})$ to martensitic $(0.5 \mathrm{~kJ} / \mathrm{mm})$, due to the markedly different cooling rates accompanying the respective thermal cycle. For a given heat input (e.g., $0.5 \mathrm{~kJ} / \mathrm{mm}$ ), there is a significant change in microstructure across the HAZ, ranging from martensitic in the CGHAZ to acicular ferrite in the base metal (BM). Grain size also changes, e.g., the average grain size in the CGHAZ $(0.5 \mathrm{~kJ} / \mathrm{mm}$ heat input) reaches $35 \mu \mathrm{m}$ compared with $5 \mu \mathrm{m}$ in the FGHAZ.

Precipitate evolution is also affected by heat input. Fig. 3a is a TEM BF image obtained from a carbon replica of the CGHAZ from a $0.5 \mathrm{~kJ} / \mathrm{mm}$ weld. A large $(>300 \mathrm{~nm})$ partially dissolved Ti-rich carbonitride is visible. A DF image (Fig. 3b) obtained from part of the (111) and (200) reflections of the SAD pattern (Fig. 3c) shows the location of the fine Nb-rich carbonitrides $(<5 \mathrm{~nm})$ that reprecipitated during the cooling leg of the weld thermal cycle. The fine precipitates are only present on or immediately adjacent the larger precipitates, which is in contrast to the uniform distribution (within grains (Fig. 4a) and along grain boundaries (Fig. 4b)) of reprecipitated fine particles in the $2.5 \mathrm{~kJ} / \mathrm{mm}$ weld CGHAZ. The difference in precipitate evolution can be attributed to the different cooling rates accompanying the 2 extremes of heat input $(0.5$ and $2.5 \mathrm{~kJ} / \mathrm{mm})$ [3]. In both cases, all smaller precipitates $(<30 \mathrm{~nm})$ are dissolved during heating to $\sim 1200^{\circ} \mathrm{C}$. For a heat input of 0.5 $\mathrm{kJ} / \mathrm{mm}$, the rapid cooling suppresses general reprecipitation within the grains; reprecipitation is 
restricted to localized regions around partially dissolved larger precipitates which had become enriched in microalloying elements. For a heat input of $2.5 \mathrm{~kJ} / \mathrm{mm}$, cooling rates are slow enough to allow uniform reprecipitation.

\section{References}

[1] K. Easterling, Introduction to the Physical Metallurgy of Welding, Butterworth-Heinemann, Oxford, 1992

[2] M.J. Godden et al., Microstruct. Sci. 9 (1981) 343.

[3] M.F. Ashby et al., Acta Metall. 30 (1982) 1969.

[4] This research was supported by the Natural Sciences and Engineering Research Council of Canada (NSERC) and IPSCO Inc. The FIB samples were prepared by Fibics Inc.

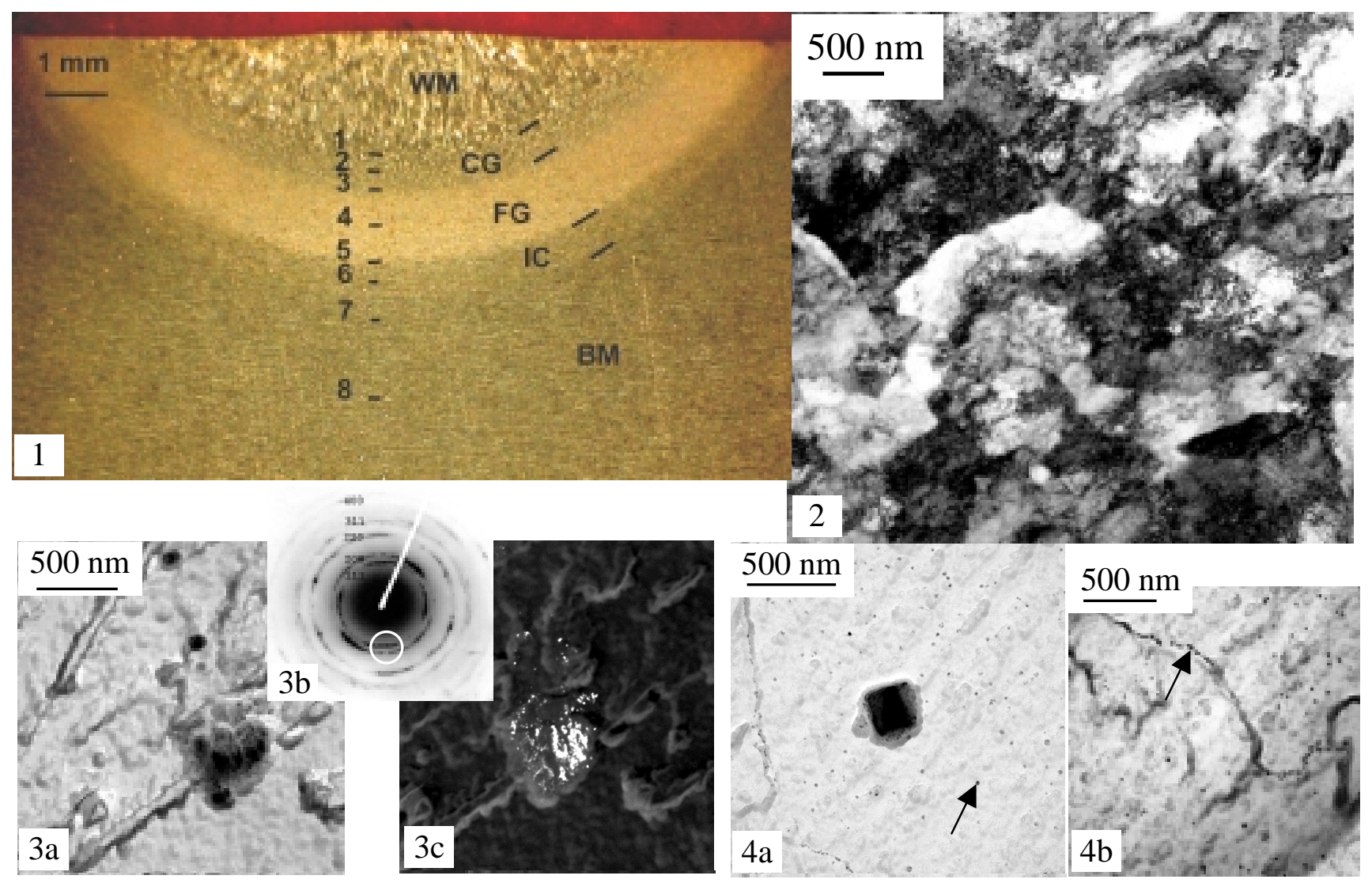

FIG. 1. Weld HAZ macrostructure of $0.5 \mathrm{~kJ} / \mathrm{mm}$ showing different regions of the HAZ, as well as the location of FIB site-specific samples.

FIG. 2. TEM BF image of the base metal prepared by FIB.

FIG. 3. a) TEM BF image from a replica sample of $0.5 \mathrm{~kJ} / \mathrm{mm}$ CGHAZ, showing a partially dissolved Ti-rich carbonitride. b) SAD pattern from (a). c) DF image from region indicated in (b). FIG. 4. a) TEM BF image from a replica sample of $2.5 \mathrm{~kJ} / \mathrm{mm}$ CGHAZ, showing an intermediatesize Ti-rich precipitate surrounded by fine precipitates. b) BF image showing a grain boundary decorated by reprecipitation of fine particles (c). 